\title{
Mineralization of synthetic polymer scaffolds: A bottom-up approach for the development of artificial bone
}

\author{
Jie Song ${ }^{1,2^{*}}$, Viengkham Malathong ${ }^{1}$ and Carolyn R. Bertozzi ${ }^{1-3^{*}}$
}

${ }^{1}$ Materials Sciences Division, Lawrence Berkeley National Laboratory, University of California, Berkeley, California 94720, USA.

${ }^{2}$ Biological Nanostructures Facility, Molecular Foundry, Lawrence Berkeley National Laboratory, University of California, Berkeley, California 94720, USA

${ }^{3}$ Departments of Chemistry and Molecular and Cell Biology, and Howard Hughes Medical Institute, University of California, Berkeley, California 94720, USA.

"E-mail: JSong@1bl.gov; crb@berkeley.edu

ABSTRACT. The controlled integration of organic and inorganic components confers natural bone with superior mechanical properties. Bone biogenesis is thought to occur by templated mineralization of hard apatite crystals by an elastic protein scaffold, a process we sought to emulate with synthetic biomimetic hydrogel polymers. Crosslinked polymethacrylamide and polymethacrylate hydrogels were functionalized with mineral-binding ligands and used to template the formation of hydroxyapatite. Strong adhesion between the organic and inorganic materials was achieved for hydrogels functionalized with either carboxylate or hydroxy ligands. The mineral-nucleating potential of hydroxyl groups identified here broadens the design parameters for synthetic bone-like composites and suggests a potential role for hydroxylated collagen proteins in bone mineralization.

\section{Introduction:}

The continued increase in the age of the population has generated higher demands for bone grafting. ${ }^{1}$ Existing orthopedic implants typically consist of a single bioinert material, such as metals, ceramics or polymers, or of a relatively coarse combination of two or three components. ${ }^{2-4}$ Although these synthetic materials provide an immediate solution for many patients, their long-term performance is generally not satisfactory. This is often due to a mechanical property mismatch between the implant and its surrounding native tissue, which ultimately leads to implant failure and tissue damage. ${ }^{5-7}$ In addition, 
these traditional implants rarely bear functionalities that encourage communication with their cellular environment, limiting the potential for self-repair, adaptation to physiological conditions, ${ }^{8}$ and tissue attachment and ingrowth. ${ }^{9}$ Finally, unlike natural skeletal tissue, where organic and inorganic components are integrated into well-defined architectures at all length scales, ${ }^{7,10,11}$ existing composite implants lack a well-defined interface between their constituents.

The development of bonelike composites with improved mechanical properties and enhanced biocompatibility calls for a biomimetic approach using natural bone as a guide. Natural bone is a composite of collagen, a protein-based hydrogel template, and carbonated apatite crystals with varying compositions and microstructures (Fig. 1A). Collagen provides a structural framework for the growth of calcium apatite. ${ }^{12}$ The unusual combination of a hard inorganic material and an underlying elastic hydrogel network gives bone unique mechanical properties, such as low stiffness, resistance to tensile and compressive forces and high fracture toughness. ${ }^{7,13}$ Bone biomineralization is thought to start with the formation of transient amorphous calcium phosphates and poorly crystalline apatites. ${ }^{14-16}$ These precursors then undergo several crystalline phase transitions before the more stable crystalline hydroxyapatite (HA) finally forms. ${ }^{11}$ The stabilization of amorphous calcium phosphate in the early stage of bone mineralization, and the subsequent formation of nanometer-sized particles, are believed to be mediated by anionic proteins attached to collagen (Fig. 1A, B). ${ }^{17-19}$ The exact role of individual acidic matrix proteins in mineralization, however, is still far from understood.

We are interested in a "bottom-up" approach to the design and synthesis of artificial bone. This entails the design of simple model systems with well-defined chemical, physical and biological properties, followed by an iterative increase in the complexity of the system to realize a higher-order approximation of natural bone. Impressive progress has been made in this direction, with some recent examples demonstrating that bonelike properties can be engendered in wholly synthetic systems. ${ }^{20,21}$ Here we describe an approach for recapitulating bone biogenesis by using hydrogel polymers functionalized to mimic the mineral-nucleating proteins of bone (Fig. 1B). We synthesized crosslinked polymethacrylamides and polymethacrylates containing biomimetic mineral-nucleating ligands and investigated their integration with calcium phosphates (Fig. 1C, D) using a recently developed ${ }^{22}$ mineralization approach. We discovered that the morphology and crystallinity of the mineral, as well as the binding strength at the polymer-mineral interface, were governed by the structure and density of the templating ligands. These results provide a framework for generating synthetic composites with defined organic/inorganic interfaces similar to natural bone.

\section{Results:}

Our first goal was to develop a 3-dimensional scaffold for HA mineralization that could be functionalized with anionic groups similar to glutamate-, aspartate- and phosphoserine-rich bone 
proteins. ${ }^{17-19}$ We chose poly(2-hydroxyethyl methacrylate) (pHEMA)-based hydrogels for this purpose due to their well-established biocompatibility and ease of functionalization. ${ }^{23-25}$ As shown in Figure 2, we synthesized a library of anionic methacrylamides. Copolymerization with either 2-hydroxyethyl methacrylate (HEMA) or 2-hydroxyethyl methacrylamide (HEMAm) ${ }^{22}$ formed 3-dimensional hydrogel copolymers. The anionic monomers varied in overall polarity and in the number of negatively charged carboxylate groups. By varying the percentage of the anionic monomers within the copolymers, the average distance between potential nucleation sites was modulated. Crosslinkers with ester (EGDMA) and amide (EGDMAm) linkages were designed to generate HEMA- and HEMAm-based hydrogels, respectively. The ester groups of EGDMA and HEMA can be cleaved under basic conditions to form the corresponding carboxylic acids, introducing additional charge into the copolymer. As discussed later, we exploited this feature for integration of calcium phosphates. By contrast, EGDMAm and HEMAm are resistant to hydrolytic cleavage. In addition to simple anionic monomers, we synthesized a monomer bearing the peptide GRGD. This sequence includes the RGD motif which is known to promote cell adhesion. ${ }^{26,27}$ All monomers and crosslinkers were synthesized via the direct coupling of the corresponding amino acid or oligopeptide with methacryloyl chloride.

The hydrogels were formed by radical copolymerization of HEMA or HEMAm and up to $10 \mathrm{wt} \%$ of an anionic monomer with $2 \mathrm{wt} \%$ of a crosslinker. The incorporation of anionic residues into the hydrogel copolymers was confirmed by equilibrium water content (EWC) measurements. ${ }^{28,29}$ As shown in Figure 3, the introduction of $10 \mathrm{wt} \%$ polar anionic ligands increased the EWC of the pHEMA-based copolymers from $40 \%(100 \%$ pHEMA) to $60-90 \%$. We also tested the biocompatibility of the functionalized hydrogels in cell culture. Human osteosarcoma TE85 cells attached, spread and proliferated on all hydrogel copolymers with no apparent cytotoxicity (supporting information).

We next evaluated the ability of the functionalized hydrogels to template HA mineralization. We have recently demonstrated that high-affinity integration of calcium phosphates with pHEMA can be realized by slowly heating the hydrogel in an acidic solution of HA in the presence of urea. ${ }^{22}$ This method takes advantage of the high and low solubilities of HA in acidic and basic solutions, respectively, ${ }^{30}$ and utilizes the thermal decomposition of urea to effect a gradual and homogeneous $\mathrm{pH}$ change in the mineralization solution. In addition, the change in both temperature and $\mathrm{pH}$ during this process promotes hydrolysis of the hydroxyethyl ester side chains of pHEMA to the corresponding carboxylic acids, thereby generating abundant $\mathrm{Ca}^{2+}$-binding sites. ${ }^{22}$

We applied the urea-mediated mineralization method to the pHEMA-based copolymers containing anionic ligands. The hydrogel copolymers were immersed in the acidic HA-urea solution at rt, and the solution was heated to $95^{\circ} \mathrm{C}$ at $0.2^{\circ} \mathrm{C} / \mathrm{min}$. We observed the mineral growth patterns shown in Figure 4. Circular mineral domains that initiated from individual nucleation sites (indicated by arrows) were 
templated by pHEMA-based hydrogels containing 5 or $10 \mathrm{wt} \%$ GlyMA, SerMA, GluMA or AspMA. After prolonged mineralization (10 additional hours at $\left.95^{\circ} \mathrm{C}\right)$, these circular mineral domains eventually merged and covered the entire surface of the hydrogel (Fig. 4F) with a thickness $>5 \mu \mathrm{m}$. A calibrated energy dispersive X-ray spectroscopy (EDS) analysis performed over the composite surface revealed a $\mathrm{Ca} / \mathrm{P}$ ratio (1.6 \pm 0.1$)$ similar to that of HA (Fig. 4A inset). X-ray diffraction (XRD) analysis (data not shown) suggested that the circular calcium phosphate domains were either amorphous or nanocrystalline, as no characteristic diffraction peaks matching those of crystalline apatites (e.g. HA) were detected. Deliberate fracturing of the composites (Fig. 4C and 4F) did not lead to delamination of any mineral domains, suggesting good mineral-hydrogel interfacial adhesion strength. This was further supported by Vickers indentation performed on selected composites. After $>10 \mathrm{~N}$ load was applied to the surface of the composites for $30 \mathrm{~s}$, the indented samples were analyzed by SEM. No delamination of the mineral domains was observed on any sample examined. The integrity of the strongly adhered circular mineral domains remained unchanged over time.

It is worth noting that the carboxylates associated with the incorporated amino acids and those generated by in situ hydrolysis of pHEMA may have both contributed to the direct and extensive mineral-hydrogel contacts responsible for the strongly adhered mineral layer. To distinguish the mineral-templating contribution of different anionic amino acid residues from that of in situ generated surface carboxylates, a hydrogel scaffold that is resistant to hydrolysis during urea-mediated mineralization was investigated. The pHEMAm-based hydrogels were designed to serve this purpose. Mineralization of pHEMAm-based hydrogels was achieved by incubating the hydrogels in acidic HAurea solution, starting at $\mathrm{rt}$ and then heating to $95^{\circ} \mathrm{C}\left(0.2^{\circ} \mathrm{C} / \mathrm{min}\right)$. The gels were then held at $95^{\circ} \mathrm{C}$ for $10 \mathrm{~h}$. As shown in Figure 5, plate-like crystals formed on all surfaces examined. These crystals, often appearing as spherical aggregates, covered the surfaces of the pHEMAm-based hydrogels containing 10 wt\% of GlyMA (Figs. 5A and 5B), SerMA (Figs. 5C and 5D), AspMA (Fig. 5E) and GluMA (Fig. 5F) residues. The morphology, XRD peaks (Fig. 5G) and $\mathrm{Ca} / \mathrm{P}$ ratio $(\sim 1.6$, Fig. $5 \mathrm{H})$ were consistent with those of crystalline HA. XRD analysis suggested that the platelets were preferentially, although not perfectly, aligned along the $c$ axis direction, as indicated by the comparable intensities of the (002), (004) and (211) peaks. For randomly oriented synthetic HA samples, intensities of (002) and (004) are usually less than 50\% of that of the main reflection (211) (Supplement information, Fig. S-2). When the $C$ axis of the thin HA crystal platelets formed in these composites are perpendicular to the hydrogel surfaces, their thin edges appear as intense lines in top view SEM micrographs (Figs. 5A-F). The additional broad peaks may be attributed to the embedded organic matrix and amorphous calcium phosphate nodules underneath the crystalline HA, which will be discussed later in more detail. 
Calcium phosphates formed on pHEMA- (Fig. 4) vs. pHEMAm- (Fig. 5) based hydrogels were different with respect to both morphology and crystallinity. Calcium phosphates formed on pHEMAbased gels create a continuous, 2-dimensional mineral layer with strong adhesive strength to the underlying matrix. By contrast, HA formed on pHEMAm-based gels nucleates on the gel surface but then propagates in 3-dimensions without extensive surface interactions. We attribute these differences to the additional anionic groups formed in pHEMA-based gels during the mineralization process, which presumably increase the number of strong calcium phosphate binding sites on the gel surface.

For hydrogels based on pHEMAm, the morphology and crystallinity of calcium apatites was independent of the structure of the biomimetic anionic ligands. AspMA-, GluMA-, SerMA- and GlyMA-containing copolymers were equally capable of mediating mineralization. This observation is in agreement with the interchangeable nucleating role of Asp and Glu residues, for instance, in bone sialoproteins as suggested by site-directed mutagenesis studies. ${ }^{31}$

As a control, we also examined whether 100\% pHEMAm gels lacking anionic ligands could be mineralized using the urea-mediated method described above. Unlike the $100 \%$ pHEMA gel, ${ }^{22}$ the $100 \%$ pHEMAm gel did not template the extensive growth of a strongly adhered mineral layer. Instead, isolated mineral nodules were formed across the surface of the pHEMAm gel (Fig. 5I). EDS analysis performed over the nodules showed a $\mathrm{Ca} / \mathrm{P}$ ratio of $1.5 \pm 0.1$ (inset of Fig. 5I). XRD of the composite did not reveal any characteristic reflections matching with those of crystalline HA. Thus, our results suggest that the hydroxyl groups of pHEMAm can template the formation of calcium phosphate, yet in a way that is markedly different from gels functionalized with anionic residues.

The formation of calcium phosphate nodules on the surface of $100 \%$ pHEMAm prompted us to reexamine the mineralized pHEMAm-based hydrogels containing various anionic ligands. When the composites were tilted by $50^{\circ}$, the SEM indeed revealed that similar nodules had formed beneath almost all spherical clusters of plate-like HA crystals. A representative SEM micrograph of composites formed with p(HEMAm-co-10\%GlyMA) is shown in Figure 5J, with the nodules appearing in darker color (indicated by arrows) and the spherical aggregates of crystalline HA platelets appearing in white. X-ray elemental mapping of $\mathrm{Ca}$ (Fig. 5K) and P (Fig. 5L) within the same sample area confirmed that both the nodules and the plate-like crystals were composed of $\mathrm{Ca}$ and $\mathrm{P}$.

\section{Discussion:}

We have developed a system for templated mineralization of calcium phosphates on organic hydrogels functionalized to mimic bone matrix proteins. The results highlight the importance of anionic $\mathrm{Ca}^{2+}$-binding sites at a critical density for high-affinity integration of the inorganic and organic 
materials. The generation of a continuous layer of amorphous or nanocrystalline calcium phosphate that strongly adheres to the pHEMA-based hydrogels provides additional possibilities for fine-tuning the mechanical properties of bone-like composite materials. In natural calcified tissues, the isotropic and less brittle amorphous mineral components, ${ }^{14,16,32,33}$ rather than their harder, stiffer and less soluble crystalline counterparts, are thought to contribute to resistance to crack propagation. ${ }^{33}$ New strategies for integrating an organic matrix with both amorphous and crystalline minerals, as demonstrated in this work, should help bridge the gap between synthetic and natural composite materials.

The distinctively different calcium phosphate nodules and plate-like HA crystals formed on the pHEMAm-based scaffolds demonstrated that both hydroxyl and carboxylate groups may be capable of templating the growth of calcium phosphates. Conventional wisdom has focused overwhelmingly on acidic non-collagenous ECM proteins ${ }^{17-19,34}$ as modulators of natural bone biomineralization. The mineral-nucleating potential of neutral hydroxyl groups identified here, coupled with evidence from other synthetic systems, ${ }^{35,36}$ suggests a plausible involvement of collagens in modulating mineral growth. The regularly occurring hydroxyamino acids in the triplet repeats of collagen ${ }^{37,38}$ may be involved in stabilizing transient amorphous calcium phosphate and in guiding the growth of small crystallites into larger apatite crystals that eventually fill the space between collagen fibers. ${ }^{39,40}$

The model system described here provides a platform for deriving basic rules for the design of synthetic bone-like composites, and for fundamental studies of the biomineralization process. These synthetic models do not possess the level of sophistication of natural bone. ${ }^{40}$ Nonetheless, by manipulating the structure and density of mineral-binding ligands presented on the hydrogels, we demonstrated that wholly synthetic organic matrices can be integrated with biominerals with varied affinity, morphology and crystallinity. To further bridge the gap between synthetic bone-like materials and natural bone, more intelligent use of the information obtained from both the "top-down" and the "bottom-up" approaches will be necessary.

\section{Experimental Section}

1. Synthesis. 1.1. General techniques. Flash chromatography was performed with $60 \AA$ silica gel (Merck, 230-400 mesh). High-pressure liquid chromatography (HPLC) was performed on a Varian ProStar 210 HPLC system using a preparative Dynamax $\mathrm{C}_{18}$ reversed-phase (RP) column. NMR spectra were recorded on a Bruker DRX-500 spectrometer. Chemical shifts of ${ }^{13} \mathrm{C} N M R$ in $\mathrm{D}_{2} \mathrm{O}$ are reported using dioxane as a reference. Low-resolution electrospray ionization mass spectrometry (ESI-MS) was performed on a Hewlett-Packard 1100 mass spectrometer. High-resolution mass spectra (HRMS) were recorded at the Mass Spectrometry Facility at the University of California at Berkeley using either fast atom bombardment $(\mathrm{FAB})$ or electrospray ionization (ESI). 
1.2. EGDMAm. To $10 \mathrm{~mL}$ of an ice-cold methanolic solution of ethylenediamine $(0.40 \mathrm{~mL}, 6.0$ mmol) was slowly added $1.24 \mathrm{~mL}(12.6 \mathrm{mmol})$ of methacryloyl chloride dissolved in $10.0 \mathrm{~mL}$ of THF. Potassium hydroxide ( $1 \mathrm{M}$, aqueous) was added to maintain the solution at $\mathrm{pH} 8-9$ throughout the reaction. The mixture was warmed to $\mathrm{rt}$ and stirred for $4 \mathrm{~h}$ before it was quenched with Amberlite IR$120\left(\mathrm{H}^{+}\right.$form $)$ion exchange resin to a final $\mathrm{pH}$ of 5. After silica gel chromatography (19:1 $\left.\mathrm{CHCl}_{3} / \mathrm{MeOH}\right)$, EGDMAm was isolated in $71 \%$ yield. ${ }^{1} \mathrm{H} \mathrm{NMR}\left(500 \mathrm{MHz}, \mathrm{CDCl}_{3}\right): \delta 6.83(2 \mathrm{H}$, br), $5.75(2 \mathrm{H}, \mathrm{d}, J=1.0 \mathrm{~Hz}), 5.35(2 \mathrm{H}, \mathrm{d}, J=1.0 \mathrm{~Hz}), 3.50(4 \mathrm{H}, \mathrm{t}, J=2.5 \mathrm{~Hz}), 1.96(6 \mathrm{H}, \mathrm{s}) ;{ }^{13} \mathrm{C} \mathrm{NMR}(125$ $\left.\mathrm{MHz}, \mathrm{CDCl}_{3}\right): \delta 169.62,139.26,120.35,40.38,18.53$; HRMS FAB ${ }^{+}(\mathrm{NBA}): \mathrm{C}_{10} \mathrm{O}_{2} \mathrm{~N}_{2} \mathrm{H}_{17}[\mathrm{M}+\mathrm{H}]^{+}$ calcd, 197.1290; found, 197.1287.

1.3. Amino acid methacrylamides. To a solution of the amino acid $(25.0 \mathrm{mmol})$ in $60 \mathrm{~mL}$ of $\mathrm{THF} / \mathrm{H}_{2} \mathrm{O}\left(\mathrm{pH} 8-9,0{ }^{\circ} \mathrm{C}\right)$ was added methacryloyl chloride $(27.5 \mathrm{mmol})$ dissolved in $20 \mathrm{~mL}$ of $\mathrm{THF}$ portion-wise over $10 \mathrm{~min}$. Potassium hydroxide (2M, aqueous) was used to maintain a $\mathrm{pH}$ of 8-9 throughout the course of the reaction. The reaction was allowed to warm to $\mathrm{rt}$ and stirred for $3 \mathrm{~h}$ before it was neutralized with aqueous $\mathrm{HCl}$ and stored at $4^{\circ} \mathrm{C}$ overnight. ${ }^{41,42} \mathrm{THF}$ was removed in vacuo and the $\mathrm{pH}$ was adjusted to 4-5 before the crude product was lyophilized. Salts were removed by precipitation from ice-cold $\mathrm{MeOH}$. The desalted product was concentrated in vacuo to afford a foamy solid which was further purified by silica gel chromatography. Yields were 30-80\%. Unwanted polymerization during either the coupling or the workup step contributed to the lower yields. GlyMA. ${ }^{1} \mathrm{H}$ NMR (500 MHz, D $\left.2 \mathrm{O}\right): \delta 5.68(1 \mathrm{H}, \mathrm{d}, J=1.0 \mathrm{~Hz}), 5.39(1 \mathrm{H}, \mathrm{d}, J=0.5 \mathrm{~Hz}), 3.84(2 \mathrm{H}, \mathrm{s}), 1.84(3 \mathrm{H}$, $\mathrm{s}) ;{ }^{13} \mathrm{C}$ NMR $\left(125 \mathrm{MHz}, \mathrm{D}_{2} \mathrm{O}\right): \delta$ 174.59, 171.58, 138.38, 121.86, 42.08, 17.55; LRMS FAB ${ }^{+}$: $\mathrm{C}_{6} \mathrm{O}_{3} \mathrm{NH}_{10}[\mathrm{M}+\mathrm{H}]^{+}$calcd, 144; found, 144. SerMA. ${ }^{1} \mathrm{H}$ NMR $\left(500 \mathrm{MHz}, \mathrm{D}_{2} \mathrm{O}\right): \delta 5.65(1 \mathrm{H}, \mathrm{s}), 5.38$ $(1 \mathrm{H}, \mathrm{s}), 4.37(1 \mathrm{H}, \mathrm{dd}, J=5.0,4.5 \mathrm{~Hz}), 3.83(1 \mathrm{H}, \mathrm{dd}, J=11.5,5.5 \mathrm{~Hz}), 3.80(1 \mathrm{H}, \mathrm{dd}, J=11.5,4.5 \mathrm{~Hz})$ $1.83(3 \mathrm{H}, \mathrm{s}) ;{ }^{13} \mathrm{C}$ NMR $\left(125 \mathrm{MHz}, \mathrm{D}_{2} \mathrm{O}\right): \delta 174.40,171.70,138.60,121.68,61.21,55.74,17.57$; HRMS $\mathrm{FAB}^{+}: \mathrm{C}_{7} \mathrm{O}_{4} \mathrm{NH}_{12}[\mathrm{M}+\mathrm{H}]^{+}$calcd, 174.0766; found, 174.0768. AspMA. ${ }^{1} \mathrm{H}$ NMR $\left(500 \mathrm{MHz}, \mathrm{D}_{2} \mathrm{O}\right): \delta$ $5.59(1 \mathrm{H}, \mathrm{s}), 5.33(1 \mathrm{H}, \mathrm{s}), 4.48(1 \mathrm{H}, \mathrm{dd}, J=6.5,5.5 \mathrm{~Hz}), 2.77(1 \mathrm{H}, \mathrm{dd}, J=16.5,4.5 \mathrm{~Hz}), 2.62(1 \mathrm{H}, \mathrm{dd}, J$ $=16.5,7.5 \mathrm{~Hz}), 1.79(3 \mathrm{H}, \mathrm{s}) ;{ }^{13} \mathrm{C}$ NMR $\left(125 \mathrm{MHz}, \mathrm{D}_{2} \mathrm{O}\right): \delta 176.33,175.83,171.15,138.71,121.32$, 51.06, 36.97, 17.48; HRMS FAB ${ }^{+}: \mathrm{C}_{8} \mathrm{O}_{5} \mathrm{NH}_{12}[\mathrm{M}+\mathrm{H}]^{+}$calcd, 202.0715; found, 202.0716. GluMA. ${ }^{1} \mathrm{H}$ $\operatorname{NMR}\left(500 \mathrm{MHz}, \mathrm{D}_{2} \mathrm{O}\right): \delta 5.59(1 \mathrm{H}, \mathrm{d}, J=0.5 \mathrm{~Hz}), 5.33(1 \mathrm{H}, \mathrm{d}, J=0.5 \mathrm{~Hz}), 4.17(1 \mathrm{H}, \mathrm{dd}, J=9.0,4.5$ $\mathrm{Hz}), 2.29(2 \mathrm{H}, \mathrm{t}, J=7.5 \mathrm{~Hz}), 2.06(1 \mathrm{H}, \mathrm{m}), 1.87(1 \mathrm{H}, \mathrm{m}), 1.79(3 \mathrm{H}, \mathrm{s}) ;{ }^{13} \mathrm{C} \mathrm{NMR}\left(125 \mathrm{MHz}, \mathrm{D}_{2} \mathrm{O}\right): \delta$ 178.30, 177.42, 171.39, 138.75, 121.18, 54.18, 31.07, 26.64, 17.52; $\mathrm{HRMS} \mathrm{FAB}^{+}(\mathrm{NBA}): \mathrm{C}_{9} \mathrm{O}_{5} \mathrm{NH}_{14}$ $[\mathrm{M}+\mathrm{H}]^{+}$calcd, 216.0872; found, 216.0877 .

1.4. GRGDMA. Tetrapeptide GRGD was synthesized on Rink amide-MBHA resin (0.1-0.2 mmol scale), using $N^{\alpha}$-Fmoc-protected amino acids and DCC-mediated HOBt ester activation in NMP on a 
Perkin-Elmer ABI 431A synthesizer. The peptide was purified by preparative reversed-phase HPLC in 90\% yield. HRMS ESI ${ }^{+}: \mathrm{C}_{14} \mathrm{O}_{6} \mathrm{~N}_{8} \mathrm{H}_{27}[\mathrm{M}+\mathrm{H}]^{+}$calcd, 403.2054; found, 403.2057. The N-terminus of the peptide was then coupled with methacryloyl chloride in aqueous THF ( $\mathrm{pH} 7-8$ ) at $\mathrm{rt}$ for $4 \mathrm{~h}$. The product was purified with reversed-phase HPLC in $89 \%$ yield. HRMS ESI ${ }^{+}: \mathrm{C}_{18} \mathrm{O}_{7} \mathrm{~N}_{8} \mathrm{H}_{31}[\mathrm{M}+\mathrm{H}]^{+}$calcd, 471.2316; found, 471.2315.

2. Hydrogel preparation. HEMA or HEMAm with various percentages ( 1,5 or $10 \mathrm{wt} \%)$ of functionalized methacrylamides (500 mg total) were combined with $10 \mu \mathrm{L}$ of crosslinker EGDMA (when HEMA was the main monomer) or EGDMAm (when HEMAm was the main monomer), $100 \mu \mathrm{L}$ of Milli-Q water and $150 \mu \mathrm{L}$ of ethylene glycol. To this mixture was added $50 \mu \mathrm{L}$ of aqueous sodium metabisulfite $(150 \mathrm{mg} / \mathrm{mL})$ and $50 \mu \mathrm{L}$ of aqueous ammonium persulfate $(400 \mathrm{mg} / \mathrm{mL})$. The viscous solution was then allowed to polymerize in a glass chamber and washed as previously described. ${ }^{22}$

3. Equilibrium water content (EWC) measurements. The EWC at $\mathrm{rt}$ is defined as the ratio of the weight of water absorbed by a dry hydrogel to the weight of the fully hydrated hydrogel. The amount of water absorbed by the hydrogel is determined from the weight of a freeze-dried gel (Wd) and the weight of the corresponding hydrated gel (Wh) according to the following equation:

$\operatorname{EWC}(\%)=[(\mathrm{Wh}-\mathrm{Wd}) / \mathrm{Wh}] \times 100$

4. Formation of hydrogel-calcium phosphate composites. A urea-mediated mineralization method 22,28 was applied to pHEMA- and pHEMAm-based copolymers containing various percentages of anionic ligands. In a typical procedure, a strip of hydrogel copolymer $(\sim 11 \mathrm{~mm} \times 20 \mathrm{~mm} \times 1 \mathrm{~mm})$ was immersed in $15 \mathrm{~mL}$ of an acidic aqueous solution of $\mathrm{HA}(15 \mathrm{mg} / \mathrm{mL}, \mathrm{pH} 2.5)$ containing $2 \mathrm{M}$ urea. The solution was heated without stirring from $\mathrm{rt}$ to $95^{\circ} \mathrm{C}$ at a constant heating rate of $0.2^{\circ} \mathrm{C} / \mathrm{min}$, and maintained at $95^{\circ} \mathrm{C}$ for 0 or $10 \mathrm{~h}$. A detailed experimental setup was described previously. ${ }^{28}$

5. Hydrogel-mineral composite characterization. Mineralized hydrogel strips were repeatedly washed in water to remove loosely attached minerals and soluble ions before they were freeze-dried for further structural analyses and mechanical characterization. The surface microstructures and crystallinity of the minerals grown on the surface of the hydrogel were analyzed by scanning electron microscopy (SEM) with associated energy dispersive spectroscopy (EDS) and X-ray powder diffraction (XRD).

5.1. SEM-EDS. All SEM micrographs of hydrogel-mineral composites were obtained with a ISI-DS 13OC dual stage SEM with associated EDS. Samples were coated with either Au on a BAL-TEC, SCD 050 sputter coater to achieve optimal imaging results, or coated with carbon for EDS analysis. All images were acquired at $15 \mathrm{kV}$. EDS analyses were performed with a $15^{\circ}$ tilt unless otherwise specified. The determination of $\mathrm{Ca} / \mathrm{P}$ ratios of all composite materials were based on calibration using a standard synthetic HA sample. 
5.2. XRD. The presence and overall orientation of crystalline phases in the precipitated mineral layers were evaluated by XRD with a Siemens D500 instrument using $\mathrm{Cu} \mathrm{K \alpha}$ radiation. Phases were identified by matching the diffraction peaks to the JCPDS files.

5.3. Indentation of hydrogel-mineral composites. The adherence of the mineral layers attached to the pHEMA-based hydrogel copolymers was qualitatively evaluated by indenting freeze-dried hydrogel-mineral composites. Loads from 5-15 $\mathrm{N}$ were applied by a Vickers indenter for 30s for each measurement. After indentation, the samples were analyzed by SEM to check for delamination of mineral layers. Lack of delamination was interpreted as an indication of strong adhesion between the mineral and the hydrogel substrate.

Acknowledgements: The authors would like to thank Dr. Eduardo Saiz for technical advice and helpful discussions regarding SEM and XRD analyses. This work was supported by the Laboratory Directed Research and Development Program of Lawrence Berkeley National Laboratory under the Department of Energy Contract No. DE-AC03-76SF00098 and the National Institute of Health grant No. R01 DE015633-01.

Supporting Information Available: Evaluation of the biocompatibility of pHEMA-based hydrogel copolymers via in vitro cell culture. This material is available free of charge via the Internet at http://pubs.acs.org.

\section{REFERENCES}

(1) Hall, M. J.; Owings, M. F. 2000 National Hospital Discharge Survey; National Center for Health Statistics: Hyattsville, Maryland, 2002; Vol. 329.

(2) Thomson, R. C.; Yaszemski, M. J.; Powers, J. M.; Mikos, A. G. Biomaterials 1998, 19, $1935-$ 1943.

(3) Marra, K. G.; Szem, J. W.; Kumta, P. N.; DiMilla, P. A.; Weiss, L. E. J. Biomed. Mater. Res. 1999, 47, 324-335.

(4) Ma, P. X.; Zhang, R. Y.; Xiao, G. Z.; Franceschi, R. J. Biomed. Mater. Res. 2001, 54, $284-293$.

(5) Black, J. Biological performance of materials: fundamentals of biocompatibility; 3rd, rev. and expanded ed.; Marcel Dekker: New York, 1999.

(6) Hillsley, M. V.; Frangos, J. A. Biotechnol. Bioeng. 1994, 43, 573-581.

(7) Weiner, S.; Wagner, H. D. Annu. Rev. Mater. Sci. 1998, 28, 271-298.

(8) Piehler, H. R. MRS Bull. 2000, 25, 67-70.

(9) Willmann, G. Adv. Eng. Mater. 1999, 1, 95-105.

(10) Vincent, J. F. V. Structural biomaterials; Rev. ed.; Princeton University Press: Princeton, N.J., 1990.

(11) Mann, S. Biomineralization: principles and concepts in bioinorganic materials chemistry; Oxford University Press: Oxford; New York, 2001.

(12) Landis, W. J.; Hodgens, K. J.; Arena, J.; Song, M. J.; McEwen, B. F. Microsc. Res. Tech 1996, 33, 192-202. 
(13) Baron, R. In Handbook of experimental pharmacology; Abou-Samra, A. B., Mundy, G. R., Martin, T. J., Eds.; Springer: Berlin; New York, 1993; Vol. 107, pp 111-147.

(14) Roberts, J. E.; Heughebaert, M.; Heughebaert, J. C.; Bonar, L. C.; Glimcher, M. J.; Griffin, R. G. Calcif. Tissue Int. 1991, 49, 378-382.

(15) Roberts, J. E.; Bonar, L. C.; Griffin, R. G.; Glimcher, M. J. Calcif. Tissue Int. 1992, 50, $42-48$.

(16) Kim, H.-M.; Rey, C.; Glimcher, M. J. Calcif. Tissue Int. 1996, 59, 58-63.

(17) Hunter, G. K.; Goldberg, H. A. Biochem. J. 1994, 302, 175-179.

(18) George, A.; Bannon, L.; Sabsay, B.; Dillon, J. W.; Malone, J.; Veis, A.; Jenkins, N. A.; Gillbert, D. J.; Copeland, N. G. J. Biol. Chem. 1996, 271, 32869-32873.

(19) Boskey, A. L. Annu. Rev. NY Acad. Sci. 1995, 760, 249-256.

(20) Hartgerink, J. D.; Beniash, E.; Stupp, S. I. Science 2001, 294, 1684-1688.

(21) Lutolf, M. P.; Weber, F. E.; Schmoekel, H. G.; Schense, J. C.; Kohler, T.; Muller, R.; Hubbell, J. A. Nat. Biotech. 2003, 21, 513-518.

(22) Song, J.; Saiz, E.; Bertozzi, C. R. J. Am. Chem. Soc. 2003, 125, 1236-1243.

(23) Phillips, A. J.; Stone, J. Contact Lenses; Butterworth \& Co.: London, Boston, 1989.

(24) Oxley, H. R.; Corkhill, P. H.; Fitton, J. H.; Tighe, B. J. Biomaterials 1993, 14, 1064-1072.

(25) Flynn, L.; Dalton, P. D.; Shoichet, M. S. Biomaterials 2003, 24, 4265-4272.

(26) Massia, S. P.; Hubbell, J. A. Ann. N.Y. Acad. Sci. 1990, 589, 261-270.

(27) Ratner, B. D. J. Mol. Recognition 1996, 9, 617-625.

(28) Song, J.; Saiz, E.; Bertozzi, C. R. J. Eur. Ceram. Soc. 2003, 23, 2905-2919.

(29) Kim, S. J.; Shin, S. R.; Lee, K. B.; Park, Y. D.; Kim, S. I. J. Appl. Polym. Sci. 2004, 91, $2908-$ 2913.

(30) Nancollas, G. H.; Zhang, J. In Hydroxyapatite and Related Materials; Brown, P. W., Constantnz, B., Eds.; CRC: Boca raton, 1994, p pp73.

(31) Tye, C. E.; Rattray, K. R.; Warner, K. J.; Gordon, J. A. R.; Sodek, J.; Hunter, G. K.; Goldberg, H. A. J. Biol. Chem. 2003, 278, 7949-7955.

(32) Addadi, L.; Raz, S.; Weiner, S. Adv. Mater. 2003, 15, 959-970.

(33) Aizenberg, J.; Lambert, G.; Weiner, S.; Addadi, L. J. Am. Chem. Soc. 2002, 124, 32-39.

(34) Boskey, A. L. Connect. Tissue Res. 1996, 35, 357-363.

(35) Merten, H. L.; Bachman, G. L.: U.S. Patent 4,237,147, 1980.

(36) Han, Y.-J.; Aizenberg, J. Mat. Res. Soc. Symp. Proc. Vol.823 2004, W10.15.11-W10.15.15.

(37) Grant, M. E.; Prockop, D. J. N. Engl. J. Med. 1972, 286, 194-199.

(38) Engel, J.; Chen, H. T.; Prockop, D. J.; Klump, H. Biopolymers 1977, 16, 601-622.

(39) Glimcher, M. J.; Krane, S. M. In Biology of Collagen; Gould, B. S., Ed.; Academic Press: London, 1968; Vol. 2B, pp 68-251.

(40) Landis, W. J.; Song, M. J.; Leith, A.; McEwen, L.; McEwen, B. F. J. Struct. Biol. 1993, 110, 3954.

(41) Menon, S. K.; Bote, A. N.; Dhoble, D. A.; Rajamohanan, P. R.; Kulkarni, R. A.; Gundiah, S. Polymer 1992, 33, 2456-2458.

(42) Camail, M.; Margaillan, A.; Thuret, S.; Vernet, J. L. Eur. Polym. J. 1998, 34, 1683-1688. 
(A) Non-collagenous

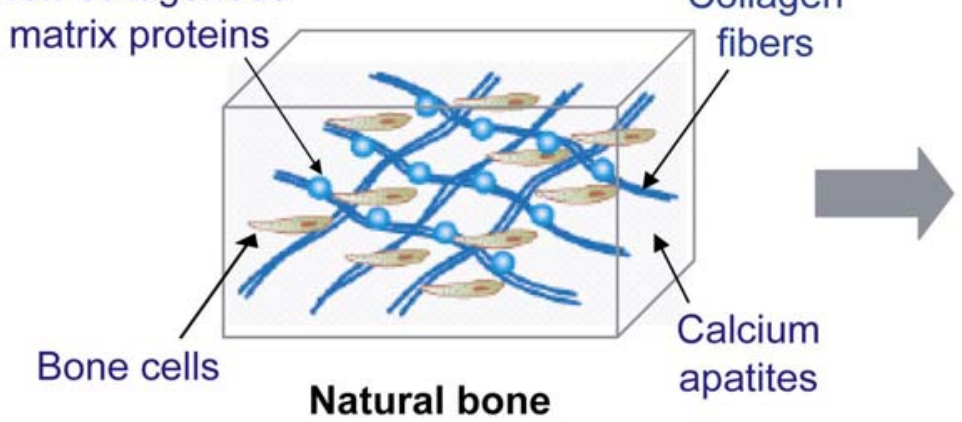

(D)

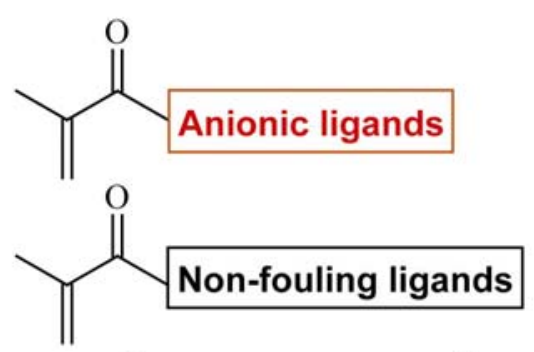<smiles>C=C(C)C(=O)CCC(C)C(=O)C(=O)C(=O)OC</smiles>

(B)

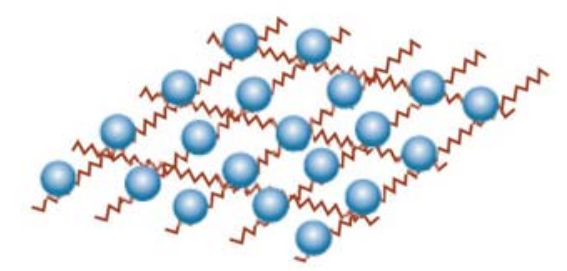

Natural organic matrix for biomineralization

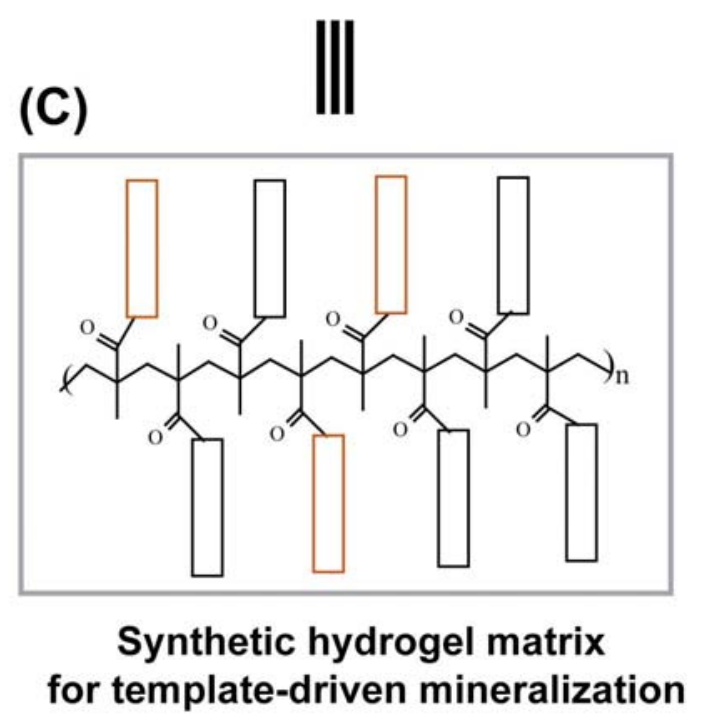

Figure 1. Recapitulating natural bone synthesis with synthetic polymers functionalized to mimic the mineral-nucleating proteins in bone. Natural bone is a biocomposite of collagen, a protein-based hydrogel template, and inorganic apatite crystals (A). The anionic non-collagenous proteins attached to the collagen matrix are thought to play important templating and regulatory roles in the bone formation and remodeling process (B). Inspired by the natural bone, polymethacrylamide / polymethacrylatebased hydrogel copolymers containing biomimetic functional domains were designed (C). Anionic residues mimicking acidic non-collagenous proteins that template the nucleation and growth of biominerals in bone are copolymerized with other monomers in aqueous media (D). 
Mineral binding monomers:<smiles>C=C(C)C(=O)NCC(=O)[O-]</smiles>

GlyMA<smiles>C=C(C)C(=O)N[C@@H](CO)C(=O)[O-]</smiles>

SerMA<smiles>C=C(C)C(=O)N[C@@H](CC(=O)[O-])C(=O)[O-]</smiles>

AspMA<smiles>C=C(C)C(=O)N[C@@H](CCC(=O)[O-])C(=O)[O-]</smiles>

GluMA

Cell adhesive monomer:<smiles>C=C(C)C(=O)NCC(=O)N[C@@H](CCCNC(=N)N)C(=O)NCC(=O)N[C@@H](CC(=O)O)C(N)=O</smiles>

Backbone monomers:<smiles>C=C(C)C(=O)OCCO</smiles>

HEMA<smiles>C=C(C)C(=O)NCCO</smiles>

HEMAm

Crosslinkers:<smiles>C=C(C)C(=O)OCCOC(=O)C(=C)C</smiles>

EGDMA<smiles>C=C(C)C(=O)NCCNC(=O)C(=C)C</smiles>

EGDMAm

Figure 2. Monomers and crosslinkers designed for polymethacrylamide- and polymethacrylatebased hydrogels. Anionic monomers, GlyMA, SerMA, AspMA and GluMA, vary in the overall polarity and the number of negatively charged carboxylates. A methacrylamide-modified peptide, GRGDMA, that possesses the RGD motif was designed to support cell adhesion. They were copolymerized with HEMA and HEMAm using the crosslinkers EGDMA and EGDMAm, respectively, to present potential mineral nucleating sites on the polymer scaffold. 


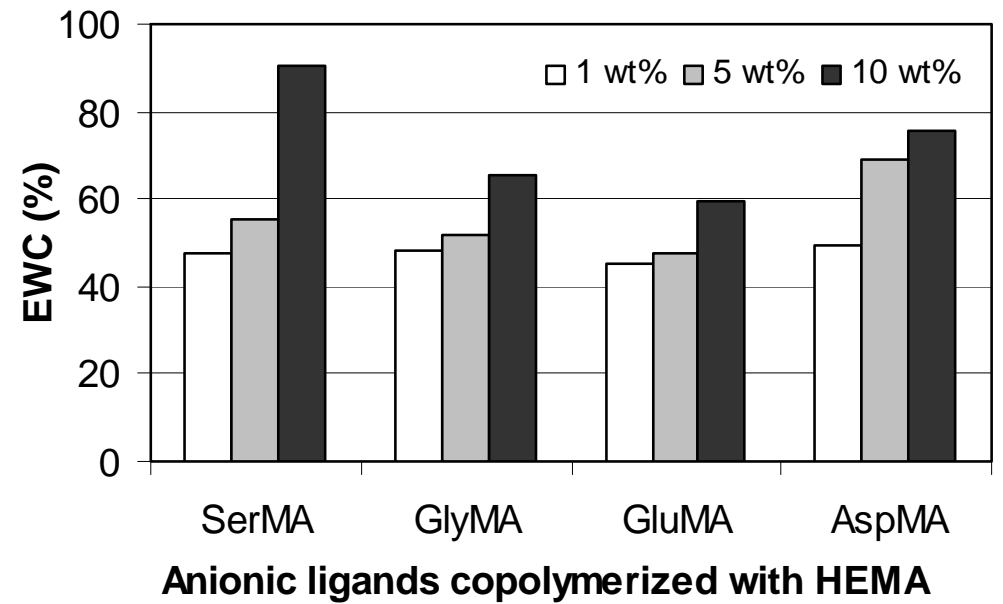

Figure 3. Equilibrium water content (EWC) of pHEMA-based hydrogel copolymers containing various percentages of anionic residues. The EWC of $100 \%$ pHEMA gel was $40 \%{ }^{19}$ 

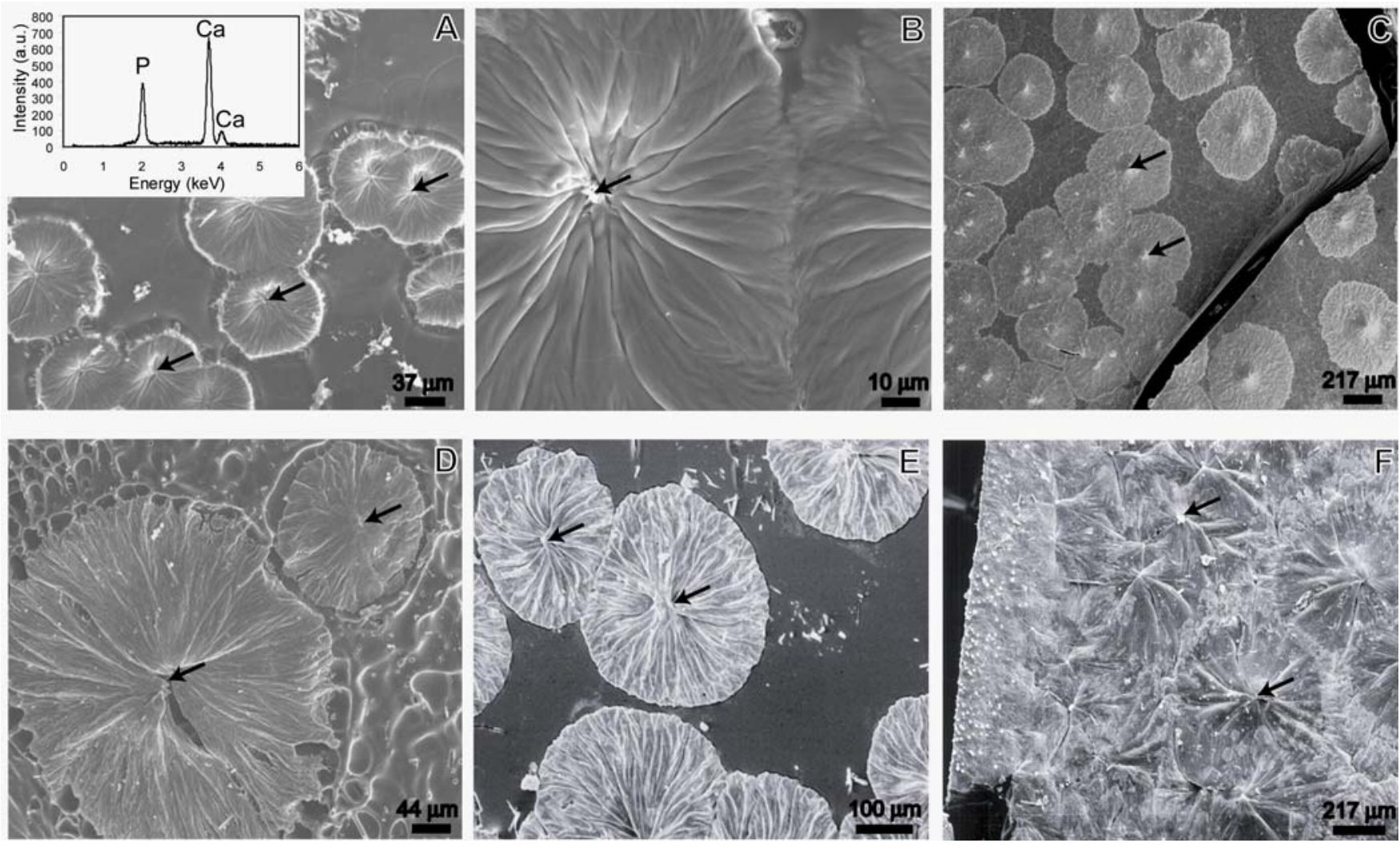

Figure 4. Urea-mediated integration of calcium phosphate with pHEMA-based hydrogel

copolymers containing various anionic residues. SEM micrographs shown are mineralized pHEMAbased hydrogels copolymerized with 5\% GluMA (A and B), 5\% GlyMA (C), 5\% SerMA (D), 10\% AspMA (E) or 10\% GluMA (F). The mineralization was performed by heating HA-urea solution from $\mathrm{rt}$ to $95{ }^{\circ} \mathrm{C}$ at a constant heating rate of $0.2^{\circ} \mathrm{C} / \mathrm{min}$, and then maintaining the sample at $95^{\circ} \mathrm{C}$ for $0 \mathrm{~h}(\mathrm{~A}-\mathrm{E})$ or $10 \mathrm{~h}(\mathrm{~F})$. Two-dimensional outward growth of circular calcium phosphate mineral domains from multiple nucleation sites (indicated by arrows) were observed on all composite surfaces. When extended mineralization was applied, the circular mineral domains eventually merged and covered the entire hydrogel surface with a final mineral layer several microns thick $(\mathrm{F})$. A representative EDS analysis (inset of $\mathrm{A}$ ) performed over the circular mineral domains of the composite revealed a $\mathrm{Ca} / \mathrm{P}$ ratio $(1.6 \pm 0.1)$ similar to that of HA. Note that the deliberate fracturing of the composites $(\mathrm{C}$, and the lower left corner of F) did not lead to delamination of the mineral layer, suggesting good mineral-gel interfacial adhesion strength. All images were acquired at $15 \mathrm{kV}$. 

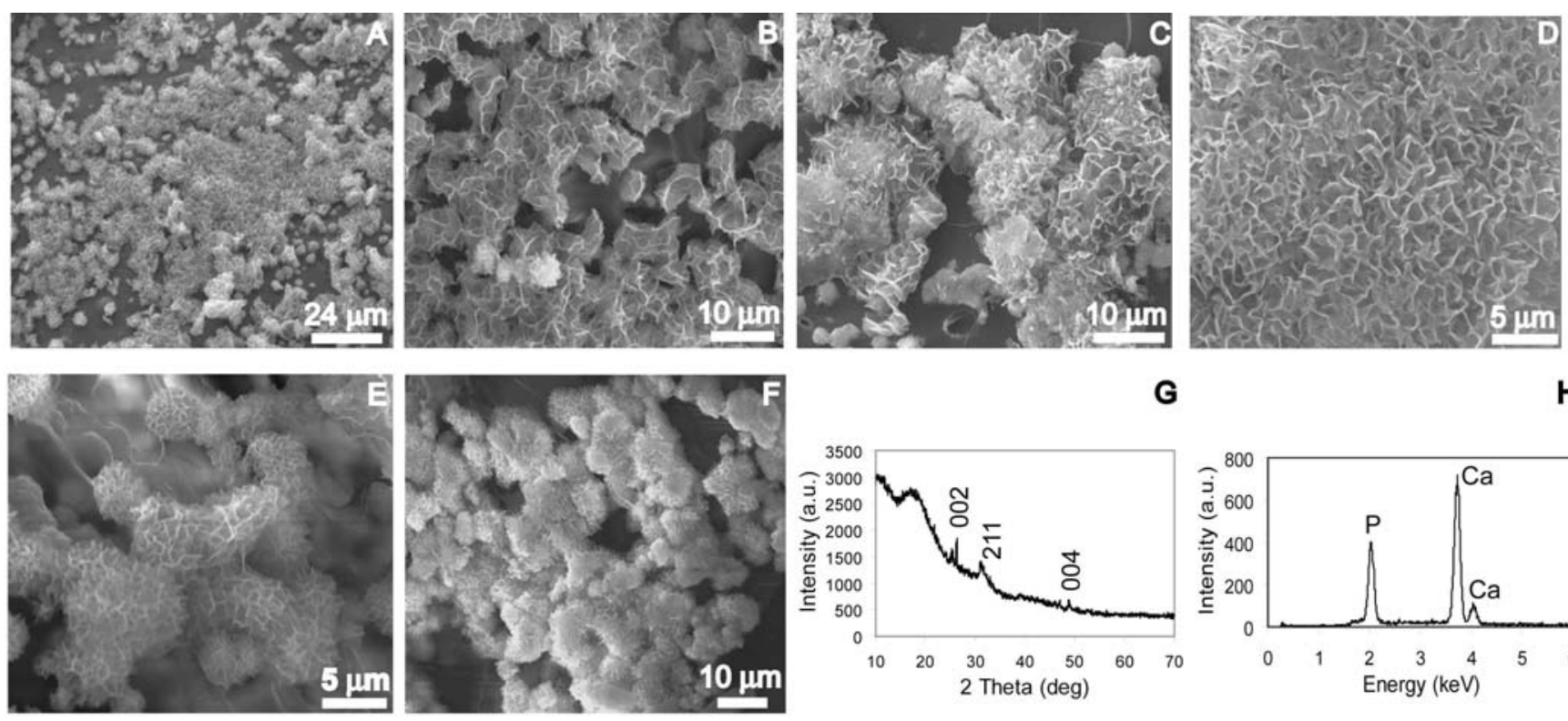

G

H
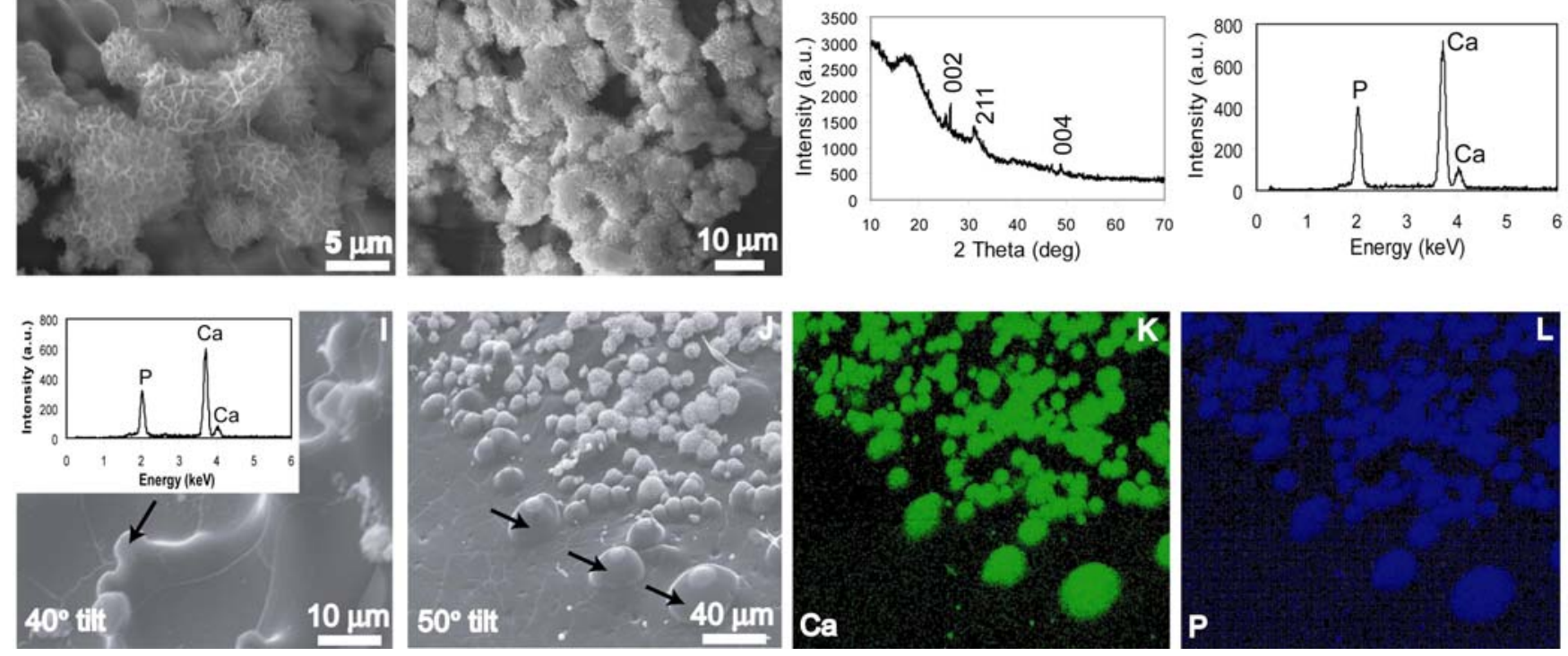

Figure 5. Urea-mediated calcium apatite growth on pHEMAm-based hydrogel copolymers

containing various anionic residues. Mineralization was performed by heating hydrogel copolymers in an acidic HA-urea solution from $\mathrm{rt}$ to $95^{\circ} \mathrm{C}$ at a constant heating rate of $0.2^{\circ} \mathrm{C} / \mathrm{min}$, and then holding at $95^{\circ} \mathrm{C}$ for $10 \mathrm{~h}$. SEM micrographs shown are mineralized pHEMAm-based hydrogels copolymerized with 10\% GlyMA (A, B and J-L), 10\% SerMA (C and D), 10\% GluMA (E), 10\% AspMA (F), and pure pHEMAm (I). Note the plate-like morphology of the crystals that aggregated on the surface of all anionic hydrogel-mineral composites. A representative XRD $(\mathrm{G})$ of the anionic hydrogel-mineral composites showed diffraction peaks characteristic of crystalline HA. An EDS analysis $(\mathrm{H})$ performed over the surface shown in (D) revealed a $\mathrm{Ca} / \mathrm{P}$ ratio of $1.6 \pm 0.1$. The selected area EDS analysis (inset of I) performed over a bulging nodule on the surface of 100\% pHEMAm (I, indicated by the arrow) suggested the mineralized nature of the nodules. A $50^{\circ}$ tilt of the p(HEMAm-co-10\%GlyMA)-mineral composite revealed similar nodules (indicated by arrows) beneath clusters of plate-like HA crystals (J). X-ray elemental mapping of $\mathrm{Ca}(\mathrm{K})$ and $\mathrm{P}(\mathrm{L})$ within the same sample area shown in $(\mathrm{J})$ confirmed that both the bulging nodules and the plate-like crystals contained $\mathrm{Ca}$ and $\mathrm{P}$. All images were acquired at 15 $\mathrm{kV}$. 


\section{TOC graphic}
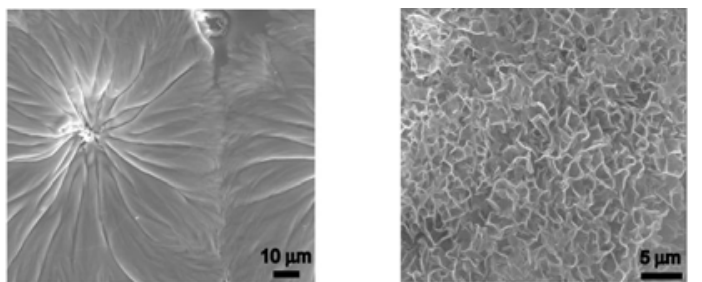

Functional hydrogels template the nucleation and growth of calcium phosphates with controled interfacial adhesion strength and crystallinity. 